\title{
Phonetic Effects of Focus in Five Varieties of Dutch
}

\author{
Judith Hanssen ${ }^{1}$, Jörg Peters ${ }^{2}$, Carlos Gussenhoven ${ }^{3}$ \\ ${ }^{1,3}$ Radboud University, Nijmegen, the Netherlands \\ ${ }^{2}$ Carl von Ossietzky University, Oldenburg, Germany \\ judithhanssen@gmail.com, joerg.peters@uni-oldenburg.de, c.gussenhoven@let.ru.nl
}

\begin{abstract}
This study examined the effects of focus on the realization of non-final nuclear falls in five varieties along the Dutch NorthSea coast. While phonetic effects surfaced more clearly in some varieties than others, we found no dialect-specific responses to the focus manipulation. In line with the findings for Standard Dutch reported in [1], focus overall affected variables associated with the falling part of the nuclear contour. The results are interpreted in terms of hyper-articulation to express differences in communicative urgency. For sentences with higher degrees of urgency, speakers sought to maximize the pronunciation of the $f_{0}$ fall inside the accented word, leading to shorter and steeper falls, which went down lower and sometimes started a little earlier. By lowering $f_{0}$ in the postnuclear stretch even further, speakers added to the communicative effect of signaling greater urgency or importance in sentences with narrow or corrective focus, compared to broad focus.
\end{abstract}

Index Terms: intonation, varieties of Dutch, focus, tonal timing, fundamental frequency, hyperarticulation

\section{Introduction}

A focus constituent in West Germanic languages can be larger than the word carrying the nuclear pitch accent that signals the focus (e.g., [2,3]). While a distinction is traditionally made between broad focus (sentence-wide) and narrow focus (applying to constituents smaller than the sentence), to use the terms used in [4], a focus constituent can have any size, including constituents smaller than the syllable when referred to metalinguistically (cf. [5]). In (1a), the focus is 'broad', while in (1b) and (1c) the object NP is in focus. In addition to size, different 'focus types' have been distinguished. The focus meaning of (1a) and (1b) is 'informational' [6], while (1c) is 'corrective' (e.g. [7]). This systematic focus ambiguity in size and type is illustrated in (1), where the focus constituent is indicated by square brackets.
a. Broad
What's happening?
(informational) [They're drinking COFFEE]
b. Narrow What are they drinking?
(informational) They're drinking [COFFEE].
c. Narrow Are they drinking milk?
(corrective) (No.) They're drinking [COFFEE].

While $(1 \mathrm{a}, \mathrm{b}, \mathrm{c})$ are generally analyzed as having the same phonological form, the difference in focus constituent size and focus type may have phonetic effects. Cross-linguistically, higher degrees of urgency or significance are associated with prominence-increasing properties, such as higher and later or earlier peaks; larger, steeper and longer fo excursions, and longer segmental durations (e.g., 8,9,10,11,12). Within West-
Germanic, focus-related phonetic enhancement has been demonstrated for German [13,14,15,16], Dutch $[1,17]$ and to a lesser extent for English [18].

There may be different motivations for speakers to enhance the perceivability of their speech. One is to promote that phonological contrasts are sufficiently distinctive, as happens in English when the laryngeal coda contrast is enhanced by vowel duration differences, as in the contrast between seed and seat or strive and strife $[19,20]$. Another is immediately relevant to our topic, which is to promote the perception of meaning by pronouncing semantically significant morphemes more carefully [21,22]. Since the phonological specification of intonational morphemes is notoriously localized, leaving sizeable stretches of speech tonally unspecified, the phonetic nature of enhancement may reveal where such specifications are located.

In a pilot experiment [1], we found that when a risingfalling nuclear pitch accent in Dutch is enhanced under intensification of the focus meaning, the enhancement is concentrated in the falling part. The low tone following the nuclear peak in narrow and corrective focus pitch accents was scaled lower and timed earlier, leading to a larger and steeper falling movement. The accent peak was timed slightly earlier but was otherwise unaffected. We found no effect of focus on the rise leading up to the nuclear peak. A small lengthening effect was found in the onset of the accented syllable. Effects were mainly between broad focus accents on the one hand and narrow and corrective focus accents on the other. Put differently, we found evidence for phonetic effects of focus size, but not focus type. The suggestion was therefore made that in Dutch the falling part of the nuclear accent is communicatively more important, suggesting an off-ramp analysis of the accent (i.e., $\mathrm{H}^{*} \mathrm{~L}$ rather than $\mathrm{L} * \mathrm{H}$ ).

The phonetic effects of focus found in other research can also be interpreted in terms of enhancement. However, most studies show enhancement in the nuclear peak and the part leading up to that peak, rather than the postnuclear stretch. In German, higher information values are associated with later and higher peaks, longer and larger rising pitch movements, and longer segmental durations $[14,15]$. The same effects were demonstrated in [16] for narrow focus accents in non-final position, but in final position, narrow focus was mostly expressed through steeper falls after the nuclear peak. Since the nuclear accents in our pilot experiment were non-final, the effects on the falling part of the pitch accent are unexpected. They are also unexpected if we consider the results of [17], which investigated the effect of differences in focus size smaller than the nuclear accented word in a number of varieties of Dutch and Low and High German. That investigation yielded no significant effect of focus size on the realization of the nuclear pitch accent in narrow corrective utterances. Compared 
to the baseline (wide information focus), however, corrective focus pitch accents were realized with increased segmental durations, higher and later peaks, lower preceding valleys, and larger rise and fall excursions. The specific enhancement strategies varied per dialect. Contrary to our pilot results, [17] did not find peak retraction, nor lowering of postfocal $f o$.

The purpose of this contribution is to see if our findings for Standard Dutch can be replicated in a number of dialects of Dutch. We test the hypothesis that the falling part of risingfalling nuclear pitch accents is hyperarticulated when it is communicatively more important. To this end, we designed a reading task with syntactically and lexically identical sentences that were phonologically ambiguous with respect to the size of the focus constituent (broad vs narrow) and focus meaning (i.e., informational vs. contrastive, more specifically corrective). The declarative sentences favored a rising-falling nuclear pitch accent on a non-final syllable.

\section{Method}

\subsection{Varieties and subjects}

We made recordings in five Dutch locations: Zeelandic in ZuidBeveland (ZB), Hollandic in Rotterdam (RO) and Amsterdam (AM) (all Low Franconian), West Frisian in Grou (GR) and Low Saxon in Winschoten (WI). Data from 95 speakers were selected for analysis (17-23 speakers per variety, aged between 14-49, 40 male speakers). ZB, GR and WI speakers were bilingual with Dutch and their local language. All regional speakers and their one or both parents were raised in the selected place and spoke the indigenous variety fluently. SD recordings were included if the geographical origin of the participants could not be determined by their accent.

\subsection{Materials and procedure}

We used twelve declarative sentences of the type We willen in Manderen blijven wonen ('We want to stay in Manderen') as answers to a preceding question. Four questions elicited an answer with sentence-wide informational focus (henceforth broad focus, BF), four with narrow informational focus (NF) and four with narrow corrective focus $(\mathrm{CF})$, assuming $\mathrm{CF}$ to have a higher 'information weight' than NF, and NF than BF. Example Q/A pairs are listed in (2) for each condition.

\section{Broad focus}

A. Wat is er met jullie (What's the matter?)

B. [We willen in Manderen blijven wonen.]

Narrow focus

A. Waar willen jullie blijven wonen? (Where do you want to stay?)

B. We willen in [Manderen] blijven wonen.

\section{Corrective focus}

A. Willen jullie in Montfort blijven wonen? (Do you want to stay in Monfort?)

B. Nee, we willen in [Manderen] blijven wonen.

A non-final falling nuclear pitch accent was expected to occur on the target word Manderen, a fictitious place name. Each of the target words had the metrical pattern sww (Momberen, Memberen, Manderen and Munderen) and was followed by two verbs with the pattern sw. The onset consonant was kept constant to be able to detect durational effects. We chose $/ \mathrm{m} /$ to limit interruptions or perturbations of the $f_{0}$ signal.

The Dutch set of test sentences was used for ZB, RO and AM. West Frisian (GR) and Low Saxon (WI) have their own standardized spelling systems and we therefore translated the Dutch materials into their local varieties, keeping the rhythmic, lexical, and segmental context as comparable as possible. Both language varieties reverse the order of the modal verb and the full verb, which means that the word following the test word is variable (e.g., fytse 'to cycle', ite 'to eat', ride 'to drive' for West Frisian.

Speakers were recorded in pairs and read each part of the mini-dialogue once. The recordings were made in a quiet room either in the homes of our speakers or in a public building, using a portable digital recorder (Zoom H4) with a $48 \mathrm{kHz}$ sampling rate, 16 bit resolution and stereo format. The mini-dialogues were interspersed with 61 filler sentences (used for other experiments) and presented in a booklet in pseudo-randomized order, which was reversed for half of the subjects per variety.

To ensure that our subjects interpreted the information in the broad focus condition as all-new, these four sentences all appeared in the first block of approximately twenty sentences. NF sentences appeared in the second block and CF in the last block. In a control experiment with eight speakers of Standard Dutch, we statistically tested whether the order of presentation in block 1, 2 or 3 (ORDER) affected the phonetic realization of the nuclear pitch accent in terms of duration and $f_{0}$. We found that ORDER did not affect the timing and scaling of tonal targets, but shortened the segmental duration of words that were realized later in the reading task. In what follows, focus effects on segmental duration should therefore be interpreted with care if they are in the same direction as the effects of ORDER. In other words, if we find that CF or NF shorten segmental durations relative to NF or BF, respectively, this may be a consequence of ORDER instead of focus condition. Duration effects in the opposite direction ( $\mathrm{CF} / \mathrm{NF}$ showing longer durations compared to $\mathrm{NF} / \mathrm{BF}$ ) must be attributed to the factor Focus, although there is no way of establishing the exact degree to which differences are obscured by our confounding factor order of presentation.

\subsection{Data analysis}

Using the speech processing software Praat [23], we inserted the labels listed in (3), and stored their $f_{0}$ value (f) and time (t) to compute the dependent variables in (4). To neutralize gender differences in $f_{0}$ excursion, $f_{0}$ levels were converted to semitones re $100 \mathrm{~Hz}$. Segmental labels were placed manually at segment boundaries on the basis of visual and auditory inspection of waveform and broadband spectrogram. Tonal labels were either low (L) or high $(\mathrm{H})$. L1 and $\mathrm{H}$ were determined semi-automatically using a Praat function that traces the location of the highest or lowest $f_{0}$ value in a selected interval. L2 was determined visually by selecting the location of the highest change in the speed of the $f_{0}$ movement near the bottom line of the nuclear contour (cf. [24]). If two elbows were visible in the low-pitched section after the peak, we selected the first one.

Labels

L1 elbow before nuclear peak

$\mathrm{H} \quad \operatorname{maximum} f_{0}$ of pitch accent

L2 elbow after nuclear peak

O1 beginning of nuclear onset

V1 beginning of nuclear vowel

$\mathrm{C} 1$ beginning of nuclear coda

$\mathrm{O} 2$ beginning of onset first postnucl. unstressed syllable

O4 beginning of onset of first postnucl. stressed syllable

V4 beginning of vowel of first postnuclear stressed syllable 


\section{Variables}

ONSETDURATION of accented syllable (ms)

Accented RIMEDURATION (ms)

Accented SYLLABLEDURATION (ms)

Accented WORDDURATION (ms)

RISEDURATION (ms), RISEEXCURSION (ST)

and RISESLOPE (ST/s)

FALLDURATION (ms), FALLEXCURSION (ST)

and FALLSLOPE (ST/s)

POSTNUCLEAREXCURSION (ST)

L1_TIMING from onset (ms)

H_TiMING from nuclear vowel $(\mathrm{ms})$

L1_SCALING, H_SCALING, L2_SCALING and V4_SCALING (ST)

We analyzed the data using the Linear Mixed Effect Model procedure in SPSS, including SPEAKER and WORD as random factors, and Focus (BF/NF/CF) as fixed factor. Pairwise comparisons between the three levels of the fixed factor were carried out using the Bonferroni correction. To estimate the additional amount of variance explained by adding the fixed factor Focus to the model, as opposed to a model that only includes the random factors, we used $\Omega^{2}$, following [25]. The formula is

$$
\Omega 2=1-\frac{\text { variance residuals model random \& fixed }}{\text { variance residuals model random }}
$$

\section{Results}

\subsection{Segmental duration}

We observed a significant lengthening effect of Focus in Winschoten for ONSETDURATION $\left[\mathrm{F}(2,159)=3.70, \mathrm{p}<.05, \Omega^{2}=\right.$ $.0445]$, with $\mathrm{CF}>\mathrm{BF}, \mathrm{p}<.05$ in posthoc comparisons, and CODADuration $\left[\mathrm{F}(2,159)=3.94, \mathrm{p}<.05, \Omega^{2}=.0468\right]$, with $\mathrm{NF}>\mathrm{BF}, \mathrm{p}<.05$. Focus did not significantly affect segmental duration in any of the other varieties.

\subsection{Scaling of tonal targets}

Table 1. Estimated means of tonal scaling per variety.

\begin{tabular}{|l|l|l|l|l|l|l|l|l|}
\hline & & BF & NF & CF & & BF & NF & CF \\
\hline L1 & ZB & 6,97 & 6,84 & 6,47 & GR & 9,54 & 9,64 & 9,73 \\
H & ZB & 12,26 & 11,89 & 11,77 & GR & 18,4 & 18,4 & 18,16 \\
L2 & ZB & 6,68 & 6,49 & 6,24 & GR & 9,27 & 9,06 & 9 \\
V4 & ZB & 6,55 & 6,12 & 5,98 & GR & 10,13 & 9,01 & 9,25 \\
\hline L1 & RO & 6,3 & 5,75 & 6,11 & WI & 8,76 & 8,54 & 7,8 \\
H & RO & 13,66 & 13,72 & 13,69 & WI & 15,86 & 16,33 & 16,02 \\
L2 & RO & 5,64 & 5,37 & 5,32 & WI & 7,47 & 7,27 & 7,18 \\
V4 & RO & 5,94 & 5,22 & 5,26 & WI & 7,31 & 6,86 & 6,71 \\
\hline L1 & AM & 5,03 & 5,01 & 4,7 & & & & \\
H & AM & 12,99 & 12,84 & 11,95 & & & & \\
L2 & AM & 4,22 & 3,82 & 4,1 & & & & \\
V4 & AM & 7,4 & 6,54 & 5,86 & & & & \\
\hline
\end{tabular}

As table 1 shows, Focus generally had a lowering effect on low targets in all varieties and did not raise the high target of the nuclear peak, which was in fact lowered by FocUs in ZB and AM.

The scaling of the elbow leading up to the nuclear peak (L1_SCALING) was significantly affected in ZB, RO and WI, with $\mathrm{BF}$ higher than either $\mathrm{CF}$ or NF. $(\mathrm{ZB}[\mathrm{F}(2,166)=5.39$, $\left.\mathrm{p}<.01 \Omega^{2}=.0609\right]$ with $\mathrm{BF}>\mathrm{CF}, \mathrm{p}<.01 ; \mathrm{RO}[\mathrm{F}(2,175)=3.14$, $\left.\mathrm{p}<.05 \Omega^{2}=.0329\right]$ with $\mathrm{BF}>\mathrm{NF}, \mathrm{p}<.05$; WI $[\mathrm{F}(2,159)=4.12]$, $\mathrm{p}<.05 \Omega^{2}=0.0525$ with $\mathrm{BF}>\mathrm{CF}, \mathrm{p}<.05$.)

Focus had a significant lowering effect on peak height (H_SCALING) in ZB $\left[\mathrm{F}(2,163)=3.49, \mathrm{p}<.05 \Omega^{2}=.0438\right]$, with $\mathrm{BF}>\mathrm{CF} \mathrm{p}<.05$ and in $\mathrm{AM}\left[\mathrm{F}(2,180)=9.00, \mathrm{p}<.001 \Omega^{2}=.0910\right]$, with $\mathrm{BF}>\mathrm{CF}, \mathrm{p}<.001$ and $\mathrm{NF}>\mathrm{CF}, \mathrm{p}<.01$.
We also found a lowering effect on the elbow after the peak (L2_SCALING) in ZB $\left[F(2,163)=3.89, \mathrm{p}<.05 \Omega^{2}=.0486\right]$, with $\mathrm{BF}$ higher than $\mathrm{CF}, \mathrm{p}<.05$.

Finally, the clearest effect of Focus on scaling was found when we looked at V4_SCALING ( $f_{0}$ measured at the first postnuclear stressed vowel). Focus lowered postfocal material in all varieties, with $\mathrm{BF}$ higher than $\mathrm{CF}$ and/or NF. (ZB $\left[\mathrm{F}(2,164)=3.26, \mathrm{p}<.05 \Omega^{2}=.0383\right]$ with $\mathrm{BF}>\mathrm{CF}, \mathrm{p}<.05 ; \mathrm{RO}$ $\left[\mathrm{F}(2,178)=5.97, \mathrm{p}<.01 \Omega^{2}=.0632\right]$ with $\mathrm{BF}>\mathrm{NF}, \mathrm{p}<.01$ and $\mathrm{BF}>\mathrm{CF}, \mathrm{p}<.01 ; \mathrm{AM}\left[\mathrm{F}(2,180)=8.92, \mathrm{p}<.001 \Omega^{2}=.0902\right]$ with $\mathrm{BF}>\mathrm{CF}, \mathrm{p}<.001 ; \mathrm{GR}\left[\mathrm{F}(2,222)=19.91, \mathrm{p}<.001 \Omega^{2}=.1517\right]$ with $\mathrm{BF}>\mathrm{NF}, \mathrm{p}<.001$ and $\mathrm{BF}>\mathrm{CF}, \mathrm{p}<.001 ; \mathrm{WI}[\mathrm{F}(2,159)=5.18$, $\left.\mathrm{p}<.01 \Omega^{2}=.0633\right]$ with $\mathrm{BF}>\mathrm{CF}, \mathrm{p}<.01$.)

\subsection{Nuclear contour shape}

This section looks at the shape (duration, excursion and slope) of the rise leading up to the nuclear peak, and the shape of the subsequent fall. We found no clear pattern across varieties for the $\mathrm{L} 1 \mathrm{H} 1$ rise. The nuclear fall tended to be shorter in NF and $\mathrm{CF}$ compared to $\mathrm{BF}$, with increasing excursions and steeper slopes. Shape differences between CF and NF were not always in the expected direction. We found significant effects of Focus on both rising and falling movements in RO, AM and WI. The effect is largest in AM, where FALLDURATION is considerably shorter, while excursion is somewhat smaller, in corrective focus than in broad and narrow focus.

RISEDURATION was affected in $\operatorname{AM}[\mathrm{F}(2,184)=4.37, \mathrm{p}<.05$, $\left.\Omega^{2}=.0467\right]$, with $\mathrm{BF}>\mathrm{CF}, \mathrm{p}<.05$; and in WI $[\mathrm{F}(2,159)=6.78$, $\left.\mathrm{p}<.001 \Omega^{2}=.0786\right]$, with posthoc tests showing that $\mathrm{BF}<\mathrm{CF}$, $\mathrm{p}<.001$ and $\mathrm{NF}<\mathrm{CF}, \mathrm{p}<.05$.

RISEEXCURSION was affected in $\mathrm{RO}[\mathrm{F}(2,175)=3.22$, $\left.\mathrm{p}<.05, \Omega^{2}=.0346\right]$, with $\mathrm{BF}<\mathrm{NF}, \mathrm{p}<.05$; and in $\mathrm{WI}[\mathrm{F}(2,161)=$ $\left.3.40, \mathrm{p}<.05 \Omega^{2}=.0399\right]$, with posthoc tests showing that $\mathrm{BF}<\mathrm{CF}, \mathrm{p}<.05$.

FALLDURATION was affected in $\operatorname{RO}\left[\mathrm{F}(2,173)=5.65, \Omega^{2}=\right.$ .0686], with posthoc tests showing $\mathrm{BF}>\mathrm{NF}, \mathrm{p}<.05$ and $\mathrm{BF}>\mathrm{CF}$, $\mathrm{p}<.01$; and $\mathrm{AM}\left[\mathrm{F}(2,183)=6.284, \mathrm{p}<.01, \Omega^{2}=.0652\right]$, with $\mathrm{BF}>\mathrm{CF}, \mathrm{p}<.01$ and $\mathrm{NF}>\mathrm{CF}, \mathrm{p}<.05$.

FALLEXCURSION was affected in $\operatorname{AM}[\mathrm{F}(2,183)=6.23$, $\left.\mathrm{p}<.01, \Omega^{2}=.0644\right]$, with $\mathrm{BF}>\mathrm{CF}, \mathrm{p}<.05$ and $\mathrm{NF}>\mathrm{CF}, \mathrm{p}<.01$; and WI $\left[\mathrm{F}(2,159)=3.08, \mathrm{p}<.05 \Omega^{2}=.0406\right]$, with no significant variation in posthoc tests.

FALLSLOPE was affected in RO $[(2,175)=12.03, \mathrm{p}<.001$, $\Omega^{2}=.1255$, with $\mathrm{BF}<\mathrm{NF}, \mathrm{p}<.05$ and $\mathrm{BF}<\mathrm{CF}, \mathrm{p}<.001$.

Furthermore, the excursion from $\mathrm{H}^{*}$ to the first postnuclear syllable (POSTNUCLEAREXCURSION) was significantly smaller in $\mathrm{BF}$ than in NF and/or $\mathrm{CF}$ in $\mathrm{RO}\left[\mathrm{F}(2,176)=4.17, \mathrm{p}<.05, \Omega^{2}=\right.$ $.0468]$, with $\mathrm{BF}<\mathrm{NF}, \mathrm{p}<.05$ and $\mathrm{BF}<\mathrm{CF}, \mathrm{p}<.05$; $\mathrm{GR}[\mathrm{F}(2,223)=$ 11.11, $\left.\mathrm{p}<.001, \Omega^{2}=.0922\right]$, with $\mathrm{BF}<\mathrm{NF}, \mathrm{p}<.001$ and $\mathrm{BF}<\mathrm{CF}$, $\mathrm{p}<.05$; and WI $\left[\mathrm{F}(2,161)=4.59, \mathrm{p}<.05, \Omega^{2}=.0540\right]$, with $\mathrm{BF}<\mathrm{NF} \mathrm{p}<.05$.

\subsection{Tonal timing}

FocUs had a significant effect on tonal timing in GR and WI, with timing of both $\mathrm{L} 1$ and $\mathrm{H}$ earlier in $\mathrm{NF}$ and/or CF, compared to broad focus sentences.

L1_TIMING: GR $\left[\mathrm{F}(2,222)=5.19, \mathrm{p}<.01, \Omega^{2}=.0431\right]$, with $\mathrm{BF}>\mathrm{CF}, \mathrm{p}<.05$ and $\mathrm{NF}>\mathrm{CF}, \mathrm{p}<.05$; and $\mathrm{WI}[\mathrm{F}(2,159)=7.18$, $\left.\mathrm{p}<.001, \Omega^{2}=.0872\right]$, with $\mathrm{BF}>\mathrm{CF}, \mathrm{p}<.01$ and $\mathrm{NF}>\mathrm{CF}, \mathrm{p}<.01$. 
H_Timing: GR $\left[\mathrm{F}(2,222)=8.71, \mathrm{p}<.001, \Omega^{2}=.0728\right]$, with $\mathrm{BF}>\mathrm{NF}, \mathrm{p}<.01$ and $\mathrm{BF}>\mathrm{CF}, \mathrm{p}<.001$; and $\mathrm{WI}[\mathrm{F}(2,158)=8.31$, $\left.\mathrm{p}<.001, \Omega^{2}=.0950\right]$, with $\mathrm{NF}>\mathrm{CF}, \mathrm{p}<.001$.

The effect of focus condition on peak timing in WI is different from the other varieties, because the peak is timed later, not earlier, in NF compared to BF. This finding is in line with the narrow focus results for H_SCALING (sec. 3.3), although we have no explanation for it at present.

\section{Discussion and conclusions}

Our results show that in most of the varieties investigated, there are small differences in phonetic realization of nuclear falling contours as a function of focus condition. Segmental durations in WI were longer in the NF and CF condition than in the BF condition. Our ORDER confound may have obscured any other durational effects. Secondly, low targets were realized lower in all varieties in sentences with more intensified focus meanings. The lowering effect was most obvious in the $f_{0}$ after the elbow, which means that speakers use the postnuclear stretch to express communicative differences. An additional lowering effect on the nuclear peak could be observed for ZB and AM. ZB was not otherwise affected by FocUs. Timing effects were observed for WI and GR. Finally, the shape (duration, excursion and slope of fo movements) was most notably affected in RO, AM and WI. In AM, the effect of FOCUS on FALLDURATION as well as RISEDURATION reported in sec. 3.3 may incidentally have a phonological basis. The AM data includes both regular-peak falls and (late) half-completed falls. The latter are associated not only with later peaks, but also with shallower and longer falling movements. The longer rise and fall durations in BF sentences can be explained by a larger proportion of late-peak falls in this condition.

\subsection{Hyperarticulation}

All effects of focus reported here are well-known from the literature summarized in sec. 1 and can be interpreted in terms of hyperarticulation [26]. Hyperarticulation can increase the prominence of (parts of) an utterance, with the purpose of increasing the distinctiveness of different levels of communicative urgency [12]. More prominence, for example in the form of larger pitch excursions, can be used to signal emphasis, enthusiasm or increased importance. Conversely, smaller pitch excursions are associated with less important information or a lack of interest.

Larger pitch excursions have been reported to go hand-inhand with higher and later peaks. While this was confirmed in [17], which is based on the same set of varieties and subjects as ours, our results show earlier peaks and lowering of $f_{0}$ after the peak. Nevertheless, our results as well as those in [17] can be interpreted as hyperarticulation. As described in [27], there are two ways in which a pitch peak can be enhanced. One is by raising it, a strategy which may evolve into peak delay as a substitute for raising, on the assumption that higher peaks are reached later. The other strategy is to hyperarticulate the pitch accent of which the peak is the realization. A more careful pronunciation of a falling pitch accent in an accented syllable may seek to maximize the pronunciation of the f0 fall inside the syllable rime, leading to a steeper fall that may begin earlier and reach lower (cf. [11]). The literature on West Germanic provides evidence for both these strategies. What unifies them is that they both serve to signal the communicative importance of the pitch accent's focus constituent. We have referred to this variation as communicative urgency, which has been manipulated by changing the focus meaning (focus type) and the size of the focus constituent, whereby smaller constituents are assumed to signal greater communicative urgency.

The results of our investigation tend to confirm the strategy used by speakers of Standard Dutch [1], whereby Focus overall affected variables associated with the falling part of the nuclear contour. Sentences with higher degrees of communicative urgency are expressed by steeper falls, which go down lower and may start a little earlier. The falls are also somewhat shorter as a result of the increased steepness that is sought by the speaker. The results reported in [17] point to the other strategy of later and higher peaks to maximize pitch excursions. We currently have no explanation for when which strategy is used. We note that the corrective focus test sentences in [17] contained three levels of urgency (CF on the nuclear accented word, syllable or onset consonant), which may have triggered speakers to use increasingly higher peaks.

Just like [15], who found considerable speaker variation in the choice for particular strategies to mark focus structure, we also have not been able to identify variety-specific preferences for particular enhancement cues. Rather, the speaker's goal to hyperarticulate the fall can be attained by using a variety of strategies. We therefore support their suggestion that speakers can choose from different (phonological and phonetic) cues within a functional cluster [28] to mark focus structure.

\subsection{Focus size vs type}

Whereas the results for Standard Dutch reported in [1] suggested that speaker enhance the pronunciation of the fall as a function of focus size rather than focus type, the current study of dialects fails to show that particular distinction. We found 30 significantly different BF-CF pairs (= variation in size and type), 13 significantly different BF-NF pairs (=size), and 12 significantly different NF-CF pairs (=type).

\subsection{Contextual clues}

It is likely that our speakers used, or even preferred, other cues besides differences in the realization of intonation structures to express or interpret focus structures. The literature reports, e.g., Downstep, deaccentuation, the use of a special pitch accent for focus, or the choice for and number of prenuclear accents. Other possibilities include visual cues [29], body language, eye contact, or the shared context between discourse partners.

One unintended contextual clue to information structure in our test materials was the presence of the focus marker 'no' at the start of the corrective focus sentence. This disambiguating morpheme may have had an effect on the necessity for speakers to express the focus structure phonetically. The fact that [14], whose test material also included the contrastive focus marker nein 'no', didn't find a durational difference between contrastive and non-contrastive focus, supports this possibility.

\section{Acknowledgements}

As part of the project Intonation in Varieties of Dutch, this research is funded by the Netherlands Organization of Scientific Research (NWO). We thank Marron C. Fort and Pieter Duijf for translating the materials, Rachel Fournier and Joop Kerkhoff for technical support, and Renske Teeuw and Lian van Hoof for data collection and annotation. We are grateful to our speakers and informants for giving us their time and best efforts. 


\section{References}

[1] Hanssen, J., Peters, J., \& Gussenhoven, C. (2008). Prosodic effects of focus in Dutch declaratives. In: Proceedings of Speech Prosody 2008, Campinas, Brazil, 609-612.

[2] Schmerling, S. (1976). Aspects of English sentence stress. Austin: University of Texas Press.

[3] Gussenhoven, C. (1983). Testing the reality of focus domains. Language and Speech 26, 61-80.

[4] Ladd, D.R. (1980). The structure of intonational meaning Evidence from English. Bloomington: Indiana University Press.

[5] van Heuven, V. (1994). What is the smallest prosodic domain? In: Keating, P. (Ed.), Phonological structure and phonetic form. Papers in Laboratory Phonology III. Cambridge: Cambridge University Press, 76-98.

[6] Kiss, K.E. (1998). Identificational focus and information focus Language 74, 245-273.

[7] Gussenhoven, C. (2007). Types of focus in English. In: Lee, C., Gordon, M., Büring, D. (Eds.), Topic and focus: Cross-linguistic perspectives on meaning and intonation. Dordrecht: Springer, 83-100.

[8] Eady, S.J. \& Cooper, W.E. (1986). Speech intonation and focus location in matched statements and questions. Journal of the Acoustical Association of America 80, 402-415.

[9] Xu, Y. (1999). Effects of tone and focus on the formation and alignment of f0 contours. Journal of Phonetics 27, 55-105.

[10] Chen, Y. (2006). Durational adjustment under corrective focus in Standard Chinese. Journal of Phonetics 34, 176-201

[11] Smiljanić, R. (2006). Early vs. late focus: Pitch-peak alignment in two dialects of Serbian and Croatian. In: Goldstein, L., Whalen, D.H., \& Best, C.T. (Eds.), Papers in Laboratory Phonology 8. Berlin: Mouton de Gruyter, 495-518.

[12] Chen, Y., \& Gussenhoven, C. (2008). Emphasis and tonal implementation in Standard Chinese. Journal of Phonetics 36, 724-746.

[13] Féry, C. \& Kügler, F. (2008). Pitch accent scaling on given, new and focused constituents in German. Journal of Phonetics 36 , 680-703.

[14] Baumann, S., Grice, M., \& Steindamm, S. (2006). Prosodic marking of focus domains - categorical or gradient? In: Proceedings of Speech Prosody 2006, Dresden, 301-304.

[15] Baumann, S., Becker. J., Grice, M., \& Mücke, D. (2007). Tonal and articulatory marking of focus in German. In: Proceedings of the 16th International Congress of Phonetic Sciences (ICPhS), Saarbrücken, 1029-1032

[16] Peters, J. (2002). Intonation und Fokus im Hamburgischen Linguistische Berichte 189, 27-57.

[17] Peters, J., Hanssen, J., \& Gussenhoven, C. (2014). The phonetic realization of focus in West Frisian, Low Saxon, High German, and three varieties of Dutch. In: Journal of Phonetics 46, 185209.

[18] Sityaev, D. \& House, J. (2003). Phonetic and phonological correlates of broad, narrow and contrastive focus in English. In: Proceedings of the 15th International Conference of Phonetic Sciences (ICPhS), Barcelona, 1819-1822.

[19] Stevens, K.N. \& Keyser, S.J. (2010). Quantal theory, enhancement and overlap. In: Jornal of Phonetics 38, 10-19.

[20] Clements, G.N. (2015). TITLE. In: Rialland, A., Ridouane, R. \& van der Hulst, H. (Eds.), Features in Phonology and Phonetics. Berlin/Boston: De Gruyter Mouton, PAGES.

[21] de Jong, K.J. (1995). The supraglottal articulation of prominence in English: Linguistic stress as localized hyperarticulation. Journal of the Acoustic Society of America 97, 491-504.

[22] Ladd, D.R. (2008). Intonational Phonology. Cambridge: Cambridge University Press.

[23] Boersma, P. \& Weenink, D. (2008). Praat: doing phonetics by computer (Version 5.0.25) [computer program]. Retrieved May 31, 2008, from http://www.praat.org/.

[24] Hirst, D.J. (2005). Form and function in the representation of speech prosody. Speech Communication 46, 334-347.

[25] Xu, R. (2003). Measuring explained variation in linear mixed effects models. Statistics in Medicine 22, 3527-3541.
[26] Lindblom, B. (1990). Explaining phonetic variation: a sketch of the H \& H theory. In: Hardcastle, W. \& Marchal, A. (Eds.), Speech production and speech modelling. Dordrecht: Kluwer, 403-439.

[27] Gussenhoven, C. (2004). The phonology of tone and intonation. Cambridge: Cambridge University Press.

[28] Local, J. (2003). Phonetics and talk-in-interaction. In: Proceedings of the 15th International Conference of Phonetic Sciences (ICPhS), Barcelona, 115-118.

[29] Swerts, M., Krahmer, E., \& Avesani, C. (2002). Prosodic marking of information status in Dutch and Italian: a comparative analysis. Journal of Phonetics 30, 629-654. 